fourteen year period. Data was collected on tumour site, histology, treatments used \& endocrine complications.

$70 \%$ of children underwent surgery, $87 \%$ received chemotherapy, $40 \%$ received cranial radiotherapy, $23 \%$ received craniospinal radiotherapy and $16 \%$ children received both cranial and craniospinal radiotherapy.

$36 \%$ of survivors were diagnosed with growth hormone deficiency (all of these children had received radiotherapy). Impaired spinal growth was seen in all children who had received craniospinal radiotherapy, exacerbating short stature. $23 \%$ of children were found to have a suboptimal cortisol response; necessitating emergency hydrocortisone treatment. $20 \%$ of survivors developed hypothyroidism. Onset of hypothyroidism ranged from 1 to 5 years following treatment. $11 \%$ of survivors were diagnosed with precocious puberty; which in 1 case had masked a growth hormone deficiency.

In conclusion, this audit confirms the high prevalence of endocrine late effects in survivors of childhood brain tumours. Growth hormone deficiency was the most common, however there was a high percentage of multiple hormone deficiencies. Data support the establishment of a joint oncology and endocrinology late effects clinic; to ensure early identification and treatment of these serious complications.

\section{G105(P) INTERPRETATION OF CORTISOL LEVELS IN INFANCY IS DEPENDENT ON CLINICAL HISTORY}

doi:10.1136/archdischild-2013-304107.117

'DS Cordiner, 'HL Miles, ${ }^{2} \mathrm{MS}$ Crane, 'LE Bath. 'Endocrinology and Diabetes, Royal Hospital for Sick Children, Edinburgh, UK; ${ }^{2}$ Biochemistry, Royal Hospital for Sick Children, Edinburgh, UK

Aims To assess cortisol levels in infancy and to determine whether low cortisol levels are indicative of pathology.

Methods A retrospective study of cortisol requests in patients aged up to 64 days for 20 months until August 2012 was undertaken. Data was collected on indications for testing, subsequent results and final outcome. Cortisol was measured using the Abbott Architect Analyser.

Results 47 patients had cortisol measured. The clinical indications were assessment of hypoglycaemia $(n=16)$, adrenal insufficiency $(\mathrm{n}=13)$, jaundice $(\mathrm{n}=11)$ and hypopituitarism $(\mathrm{n}=7)$.

Cortisol was $<100 \mathrm{nmol} / 1$ in 19 patients: 7 had no further investigation; 3 proceeded directly to standard short synacthen test [SSST] and passed; 9 had repeat cortisol levels tested: 3 were above $100 \mathrm{nmol} / 1$ and 5 out of the remaining 6 had further investigation (SSST or Corticotrophin Releasing Test [CRH]) which 3 passed.

For hypoglycaemia the median cortisol was $260 \mathrm{nmol} / \mathrm{l}$ (range $42-793 \mathrm{nmol} / \mathrm{l}) .1$ patient with a random cortisol of $42 \mathrm{nmol} / 1$ passed a SSST.

For investigation of adrenal insufficiency, the median cortisol was $182 \mathrm{nmol} / 1$ (range $46-503 \mathrm{nmol} / \mathrm{l}$ ). 2 patients with random cortisols of 82 and $85 \mathrm{nmol} / 1$ passed a SSST while a third with a level of $93 \mathrm{nmol} / \mathrm{l}$ had a borderline SSST result.

For jaundice screen, the median cortisol was $132 \mathrm{nmol} / 1$ (range $<40-407 \mathrm{nmol} / \mathrm{l})$. One patient with a cortisol of $47 \mathrm{nmol} / \mathrm{l}$ went on to pass a SSST.

For hypopituitarism, the median cortisol was 40nmol/1 (range $<40-146 \mathrm{nmol} / \mathrm{l}$ ). Four children in this group with baseline cortisol levels $<40 \mathrm{nmol} / 1$ proceeded to a SSST which 3 passed. A child with suspected septo-optic dysplasia and a baseline cortisol of $87 \mathrm{nmol} / 1$ failed a CRH test. One infant with baseline of $69 \mathrm{nmol} / 1$ underwent no further testing.

Results are illustrated in graph 1.

Conclusion Reviewing this cohort of 47 patients, 3 are now known to have cortisol deficiency. In 2, the random cortisol was less than 100nmol/1 and they had additional clinical features. A 3rd patient has congenital adrenal hyperplasia, and the cortisol at presentation was $130 \mathrm{nmol} / 1$. Interpretation of a cortisol result must be undertaken with the clinical history and additional biochemical results and unless there are features indicating an underlying problem, a random low cortisol is not diagnostic.

\section{Ethics and Law Forum/British Academy of Childhood Disability}

\section{G106 NON-THERAPEUTIC CIRCUMCISION IN 'HIGH-RISK' CHILDREN IN A CHILDREN'S HOSPITAL: CONSENT AND SAFETY}

doi:10.1136/archdischild-2013-304107.118

'S Collinson, ${ }^{2} \mathrm{~J}$ Brierley. ${ }^{1}$ Medical School, St Georges, London, UK; ${ }^{2}$ Clinical Ethics Service, Great Ormond St Hospital, London, UK

Aims Non-therapeutic circumcision (NTC) is controversial. Religious freedoms and suggested health benefits are balanced against a non-medically indicated surgery in children who cannot consent.

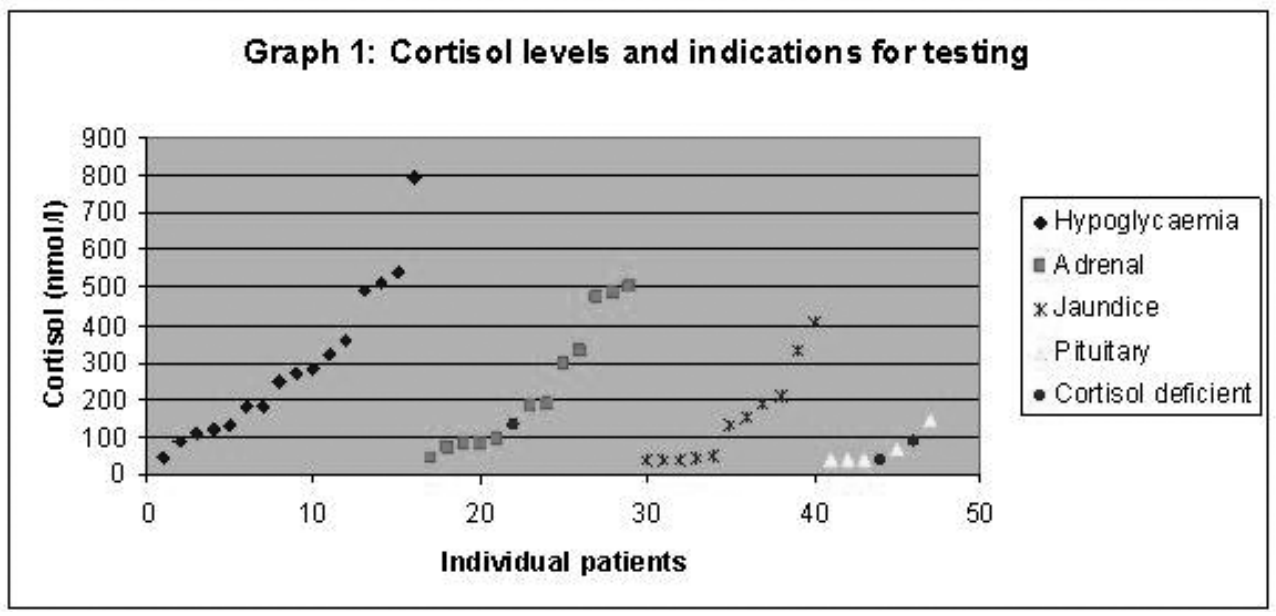

